\title{
A ideia da universidade pública: narrações contrastantes ${ }^{1}$
}

José Joaquín Brunner*

'The 'Idea of a University' changes over time in response to (1) changes in higher education and in its context, (2) changes in the discourse about the University".

Simon Marginson (2008, p. 13).

\section{Resumo}

Este trabalho trata das narrativas - ou práticas discursivas - que formam parte da autoconsciência e da ideologia da moderna universidade pública e estatal. Analiso brevemente seus modelos fundamentais e contrasto-os com algumas de suas novas manifestações em diversos cenários atuais da educação superior. Mostro que a 'ideia de universidade' pública e estatal, construída por essas narrativas, está drasticamente desligada das condições em que essa instituição existe e se desenvolve no presente. Termino propondo algumas ideias para a renovação dessas práticas discursivas na América Latina.

Palavras-chave: Universidade. Modelos históricos. Ensino. Pesquisa. Estado. Público.

\section{Introdução}

A moderna universidade pública nasce no começo do século XIX em um momento culminante de desenvolvimento do pensamento estatal, na sua dupla vertente filosófico-idealista germânica e político-burocrática francesa. $\mathrm{Na}$ literatura especializada, essas vertentes aparecem representadas, respectivamente, pelos modelos Humboldtiano e Napoleônico. Estas constituem duas poderosas narrativas: a do Estado que ampara as ciências e a formação humana em um caso, o germânico, e a do Estado-docente da nação no outro, o francês.

Em que consistem os dois modelos e suas expressões institucionais e discursivas?

1 Artigo baseado no trabalho apresentado no Fórum UPUAL 2012, "Las Universidades Públicas en América Latina: El Debate Necesario", organizado pela Universidade Autónoma Metropolitana, Unidad Xochimilco, División de Ciencias Sociales y Humanidades, México, DF., nos dias 13 e 14 de junho de 2012.

* Doutor em Sociologia pela Universidade de Leiden, professor da Universidade Diego Portales, Chile, onde dirige a Cátedra UNESCO em Políticas Comparadas de Educação Superior. 
Em suma, o modelo Humboldtiano, encarnado como um símbolo - como um mito, dizem alguns (ASH, 2006) - na Universidade de Berlim, fundada em 1810, sob a inspiração do neo-humanista e alto funcionário Wilhelm von Humboldt, propunha para a universidade um papel que superasse a mera transmissão do conhecimento útil, o de ensinar como é descoberto o conhecimento e instigar os estudantes a levar em conta as leis fundamentais das ciências (e da filosofia) em todos os processos de pensamento. Uma formação (Bildung) concebida, então, em termos classicamente aristocráticos e senhoriais (estamento ao qual von Humboldt, afinal, pertencia), afastada de qualquer instrumentalismo ou espírito vocacional. Embora esses objetivos devessem encontrar também seu lugar na universidade, não constituíam seu fim específico e mais elevado, mas apenas sua maneira de servir ao Estado (ABELLÁN, 2009; NYBOM, 2007; KWIEK, 2006; NEAVE, 2001).

Para cumprir essa missão formativa, os professores catedráticos deviam desenvolver simultaneamente o ensino e a pesquisa e utilizar o seminário como método de ensino. Por sua vez, a universidade devia usufruir das liberdades essenciais da academia - ensino, aprendizagem, pesquisa e erudição - e o Estado devia proteger essas prerrogativas, limitando-se a nomear os professores e a financiar as instituições, sem interferir na sua autonomia.

Quanto à realização dessa 'ideia de universidade' dentro do Estado moderno - como uma autonomia organizada estatalmente, de acordo com a fórmula empregada por Habermas (1997) - cabe entendê-la conforme as premissas do idealismo alemão, Hegel em particular. Recordamos que o filósofo concebia o Estado como a realização efetiva da ideia ética; "o racional em si e para si", conforme escreve na Filosofia do Direito (HEGEL, 2000, p. 302). Por sua vez, a universidade se tornava parte do Estado não apenas para unificar culturalmente a nação, mas, simultaneamente, para humanizar o Estado (FALLON, 1983).

A esta ideia, une-se outra que provêm do modelo Napoleônico de universidade e do discurso do Estado-docente. Em que consiste?

De acordo com a doutrina elaborada durante o século XIX, a educação nacional deveria estar situada no coração do projeto político-estatal; era o meio para estabelecer um espaço público e a expressão do Estado-docente (LELIÈVRE, 2000). No âmbito da educação superior, Napoleão dissolveu as universidades 
herdadas da Idade Média e criou, entre 1806 e 1808, a Universidade Imperial, que devia ser a encarregada de controlar o ensino médio e superior da nação francesa. Assim, "através da centralização da administração educacional e da nacionalização da profissão docente, o regime imperial estabeleceu uma estrutura unitária com o poder de administrar [também] o ensino privado" (VAUGHAN; ARCHER, 1973, p.143).

As antigas universidades se subdividem em faculdades separadas e desaparecem como organizações unificadas e unificadoras do conhecimento. No seu lugar, são criadas escolas profissionais especializadas, inspiradas nas doutrinas utilitárias da Ilustração. Sua função é formar as novas elites do Estado, racionalizar a administração pública e secularizar a cultura dominante. Algumas - chamadas grandes écoles - adquirem enorme prestígio, como a Escola Normal, a Escola Politécnica e outras. As faculdades de artes e letras - que abarcavam o ensino da filosofia da época - têm um papel menor neste modelo, ao contrário do que ocorria na Prússia. A pesquisa e inovação radicam em organismos especiais como o Colégio de França, o Museu de Historia Natural e as academias (CHARLE, 2004, p. 44-47).

Logo, nacionalismo, espírito vocacional e elitismo tecem a ideologia deste modelo. A educação ministrada sob esse modelo não é neutra; não poderia sê-lo. Instruções imperiais indicavam que todas as escolas da Universidade Imperial deviam tomar como base de sua instrução: (1) os preceitos da religião católica; (2) a fidelidade ao imperador, a monarquia imperial e a dinastia napoleônica; e (3) a obediência aos estatutos acadêmicos cujo objetivo era assegurar a uniformidade da instrução. (ROWE, 1982).

Afirmo que esses dois modelos ou tradições narrativas contribuíram poderosamente para moldar a identidade da moderna universidade pública estatal, a consciência dos seus atores e a visão da sociedade sobre a natureza e o papel do ensino superior. Como qualquer narrativa institucional, ela oferece uma ideologia motivadora e mobilizadora de ideias, mitos e aspirações.

Nesse caso, o núcleo da narrativa é constituído por uma ideia épica sobre a integração da universidade na esfera ético-espiritual do nascente Estado-nação e a ideia de que esse Estado, como Estado-docente, é o educador da nação, das suas elites e quadros administrativos e profissionais superiores. 


\section{As universidades públicas do Estado}

Se nos transportarmos abruptamente para os nossos dias, constataremos imediatamente que o cenário atual, no qual operam as universidades públicas do Estado e os sistemas nacionais de ensino superior, é muito diferente daquele onde foi concebida a ideia moderna de universidade. Podemos usar o clássico Triângulo de Clark (TC) para ilustrar, esquematicamente, as principais características desse cenário (CLARK, 1983). Lembremos que nos vértices do triângulo encontramse: (i) as instituições e suas 'oligarquias acadêmicas' que constituem o centro de gravidade dessas organizações; (ii) o Estado e as agências do governo, que mediante políticas, normas, regulamentações, comandos administrativos e subsídios organizam o cenário da educação superior e contribuem para o financiamento de um setor das instituições provedoras e (iii) os mercados relevantes - de estudantes, acadêmicos, recursos privados e de reputação ou prestígios - por meio dos quais as partes interessadas (stakeholders) da sociedade civil e das instituições universitárias interagem e intercambiam, cada uma em benefício próprio.

Vamos começar pelas instituições. Atualmente, o panorama quantitativo é completamente diferente. Ao finalizar o século XVIII havia na Europa 143 instituições universitárias; por volta de 1930, já em plena fase de desenvolvimento da prática moderna da universidade, seu número tinha aumentado só para 156 nessa região. Hoje, no entanto, não se sabe exatamente quantas são as instituições de ensino superior, nem como identificá-las e classificá-las. O banco de dados da Associação Internacional de Universidades registra 15.400 universidades ou instituições equivalentes (HAZELKORN, 2011), um número, sem dúvida, conservador. Por exemplo, a América Latina aparece com pouco menos de 2.000 quando, de acordo com o registro mais recente, possui umas 3.900 universidades e instituições equivalentes, além de cerca de 6.500 instituições não universitárias de ensino superior (BRUNNER; FERRADA, 2011).

Considerando apenas o universo latino-americano de universidades, podemos dizer que nenhuma - ou quase nenhuma - reúne os traços característicos do modelo Humboldtiano. De fato, o conhecimento com que trabalham não forma uma unidade orgânica indivisível; não há unidade de Forschung und Lehre, pesquisa e ensino, na graduação; em vez da primazia da pesquisa filosófica e científica, como reclamava von Humboldt, mais de $90 \%$ das universidades latinoamericanas são instituições exclusivamente de ensino; o clima de liberdade e 
solidão para perseguir individualmente ou em conjunto a verdade - que era parte do ideal Humboldtiano - foi substituído por um clima organizacional próprio de instituições de massa: barulhento e utilitário, transacional e mesocrático ou popular, direcionado para fora, coletivo e volúvel; as liberdades de ensinar e aprender como traços substantivos da vida intelectual universitária deram lugar à liberdade de escolher cursos e combinar créditos de aprendizagem, tudo isso em um meio altamente burocratizado e de carismas acadêmicos rotineiros; finalmente, a ideia central deste modelo - a criação de uma cultura nacional centrada na Wissenschaft, que vê a universidade como pivô e base de um Kulturstaat desvaneceu-se no meio da verdadeira mudança de maré provocada pelas forças dos mercados, da globalização e da transformação do Estado.

O que aconteceu nesse meio tempo na área próxima do ápice dos mercados e da sociedade civil? Não há praticamente nenhuma análise da educação superior em nível global e das diferentes regiões e países do mundo, na qual a análise do 'estado da arte' não comece mencionando processos de 'mercadização' e privatização, de comercialização e 'managerialismo', de empresarialização e 'comodificação'. Isso reflete a importância alcançada por esses fenômenos, independentemente da nossa opinião sobre eles.

O 'capitalismo acadêmico' (SLAUGHTER; RHOADES, 2004; BOK, 2003), produto de Estados burocratizados e contratualistas e de mercados expansivos, estaria gerando uma das maiores mudanças no ambiente no qual o ensino terciário é desenvolvido. Além disso, estaria provocando mudanças na orientação, papel, funções, identidade, gestão, financiamento e autopercepção das universidades estatais, como veremos adiante.

A penetração dos mercados provocou uma mudança radical na composição da oferta e na distribuição da demanda estudantil, com o surgimento, desenvolvimento e relativa consolidação de um amplo e variado setor de instituições privadas. Atualmente, a maioria das instituições de ensino superior são privadas, sem subsidio direto dos Estados. Aproximadamente um terço da população estudantil mundial está matriculada em instituições desse tipo. Na América Latina, essa proporção é, em média, de um para cada dois estudantes, mas é ainda maior no Brasil, Chile, Costa Rica, El Salvador, Paraguai e Peru. Algo parecido acontece nos países asiáticos, como Filipinas, Indonésia, Japão, Malásia e República da Coreia. Também a China e alguns países da Europa Central e do Leste mostram um crescimento dinâmico desse setor (LEVY, 2011). 
Em resumo, os sistemas nacionais de educação superior não são mais voltados exclusivamente aos estados nacionais, nem mesmo à comunidade nacional como uma esfera pública de representação cultural, mas aos mercados e às diferentes partes interessadas que constituem a sociedade civil, cujas demandas e interesses devem, agora, ser também atendidos pelas universidades. Então, é possível afirmar que o papel previsto para a universidade pelos modelos Napoleônicos e Humboldtiano perdeu sua vigência, sendo transformado de varias maneiras. Do ponto de vista do Estado, essas transformações têm pelo menos cinco vetores fundamentais.

Primeiro, o Estado perdeu o caráter de provedor monopólico do ensino superior e, com ele, em muitos lugares do mundo, o controle sobre os currículos, títulos e diplomas acadêmicos.

Segundo, o Estado - ao perder sua aura moral e de altruísmo universal hegeliano - perde também sua centralidade como referência cultural da nação e, para todos os efeitos práticos, é transformado em mais uma contraparte para a universidade.

Terceiro, o próprio Estado adquire uma visão instrumental e secularizada da universidade, ao defini-la como um meio para aumentar a produtividade do capital humano e a competitividade da economia nacional e como um dispositivo para promover a mobilidade social em chave meritocrática e a cultura racionalcientífica em benefício da modernização da sociedade civil.

Quarto, para atingir esses objetivos, o Estado redefine suas relações com as universidades em termos de um novo contrato social, que inclui: financiamento condicionado a metas e à contínua medição do desempenho; prestação de contas (accountability) das instituições perante o governo e as demais partes interessadas; monitoramento permanente e controle de qualidade realizados a distância porém de forma cada vez mais minuciosa e exigente, e obrigação das universidades de diversificar suas fontes de renda e gerar recursos em um ou mais dos mercados relevantes.

Quinto, as instituições são forçadas a rever e ajustar suas formas de governo e gestão e sua relação com o meio e com as diversas partes interessadas, procurando responder a novas e mais variadas exigências. A doutrina que inspira essas mudanças é, em geral, o New Public Management que impulsiona uma transferência de modelos e instrumentos de gestão do setor privado para 
as agências e instituições públicas (MARGINSON E CONSIDINE, 2011). Os analistas costumam interpretar essas mudanças, no caso das universidades estatais, como fenômenos de privatização e de adoção de um estilo gerencial centrado em valores de eficiência e em critérios comerciais, o que seria profundamente contrário às tradições colegiais e aos valores de altruísmo universal que haviam marcado o nascimento da universidade pública, pelo menos - é o que se afirma - sob a inspiração do modelo Humboldtiano.

\section{Novos cenários}

A propósito dos novos cenários que surgem dessas transformações no $\mathrm{TC}$, e utilizando esse mesmo dispositivo, examinarei a seguir alguns padrões e comportamentos institucionais emergentes entre as universidades públicas estatais em diferentes contextos nacionais.

\section{Instituições - Estado}

Se partirmos do vértice superior do triângulo, correspondente ao Estado, encontramos os países nórdicos, considerados até pouco tempo atrás como um paradigma da educação superior pública. Sem dúvida, os mesmos mereceram essa posição, pelo menos do ponto de vista da natureza jurídica puramente estatal das suas instituições, a composição dos alunos matriculados, o acesso gratuito, $\mathrm{o}$ seu financiamento integramente fiscal, o estatuto do professorado como parte do funcionalismo público e a integração de todos os seus sistemas com a esfera do Estado de bem-estar, com a sua concomitante e onerosa carga tributária.

O anterior não impede que o caráter público-estatal desses sistemas tenha evoluído e esteja transformando-se em muitos aspectos. Conforme apontava um estudo já em 2004, os países nórdicos estavam, em geral, redefinindo os termos do contrato entre os respectivos Estados, os sistemas nacionais e as instituições. "Uma das consequências desses movimentos recentes", indicava o estudo, "é a diminuição do poder das oligarquias acadêmicas junto com o avanço do mercado. Além disso, à medida que os governos nacionais vão atuando sob pressão das comunidades supranacionais, o papel do Estado vai ficando menos evidente" (FÄGERLIND; STRÖMQVIST, 2004, p. 245). Vale a pena ilustrar esse ponto com as transformações ocorridas ultimamente na governança (governo + gestão) das universidades da Finlândia (VALIMAA, 2012; KAUKO; DIOGO, 2011; AARREVAARA et al, 2009): 
ident

(i) Mediante a lei 558 de 2009, as universidades finlandesas foram definidas como corporações públicas, entidades legais independentes, que, por esse ato, foram separadas do Estado-nação e deixaram de ser instituições financiadas exclusivamente pelo governo. Inclusive, podem optar por transformar-se em fundações - como fizeram as universidades de Aalto e a Universidade Técnica de Tampere -, situação na qual podem, também, contratar e administrar sua própria força de trabalho.

(ii) As universidades adquirem o controle de suas propriedades, antes nas mãos do governo, passando a ser instituições com patrimônio próprio e com a faculdade de assinar contratos, receber doações e realizar investimentos. Dois terços do custo total da operação das universidades, no momento da aprovação da lei, continuarão sendo cobertos por recursos do Ministério da Educação.

(iii) Um conselho de diretores passa a ser o principal órgão de governo universitário, devendo aprovar a estratégia institucional e a nomeação da direção executiva, incluindo a nomeação do reitor. Esse organismo é composto por $40 \%$ de membros externos à universidade. Na Dinamarca, porém, os membros externos são a maioria no conselho de diretores (JENSEN, 2010; ANDERSON, 2006). O reitor é responsável pela administração institucional, pela formulação das políticas e pela execução das decisões do conselho. Ele nomeia os decanos e esses nomeiam os diretores dos departamentos, o que reforça a linha executiva da organização. O Colégio Universitário, que representa professores e estudantes, é o órgão acadêmico superior responsável por aprovar anualmente as contas prestadas pelo conselho de diretores e atuar em funções consultivas.

(iv)Finalmente, os professores deixam de ser funcionários do Estado, servidores públicos, e tornam-se funcionários da universidade com um contrato de trabalho. Isso, conforme uma análise recente, completaria o processo de corporativização das instituições universitárias: “é provável que, em uma universidade corporativa, os acadêmicos ponham em primeiro lugar a estratégia da sua instituição, enquanto que na universidade estatal os acadêmicos mantêm laços de lealdade com o Estado-nação" (VALIMAA, 2012, p. 116-117).

Como podemos notar, aqui estamos longe do modelo tradicional de uma universidade pública e também da concepção Napoleônica do Estado-docente. 
Mudemos, agora, de foco geográfico e vamos por um instante à América Latina, região onde também perdurou - embora em contexto completamente diferente do europeu - uma forte tradição de educação superior pública. As diferenças são óbvias: (i) na América Latina, predominam quantitativamente as universidades privadas; (ii) as universidades públicas, com algumas exceções em cada país, têm função principalmente de ensino; (iii) sua direção nunca admitiu um alto grau de interferência ministerial, como houve e há até hoje nas universidades públicas da Europa por parte dos ministérios de educação; (iv) no entanto, aqui, ao contrário do observado na maioria dos países da OCDE, não houve reformas de magnitude no governo e gestão das universidades públicas estatais, que mantêm até hoje o padrão inspirado na reforma de

Córdoba de 1918; (v) finalmente, não se generalizou na América Latina o uso de novos instrumentos de financiamento utilizados na Europa, nos países anglosaxões e em diversas partes da Ásia, sendo que a maior parte dos recursos provém de subsídios institucionais não-condicionados e relativamente garantidos que a gestão orçamentária de um mandato deixa para a seguinte.

\section{Estado-mercado}

Por outro lado, em outras partes do mundo, especialmente nos países desenvolvidos, as universidades públicas foram forçadas a atuar em contextos políticos e regulatórios mais exigentes. Submetidas à pressão dos governos para diversificar suas fontes de renda, operar com maior eficiência e competitividade e adaptar-se às novas circunstâncias da economia, muitas universidades estão tendo de abandonar sua tradicional posição ao amparo do Estado e tornar-se empreendedoras.

Segundo um conhecido estudo, essas instituições empreendedoras - na sua maioria, universidades públicas - reúnem, em geral, cinco características: uma liderança promotora das mudanças em nível organizacional e que, portanto, não bloqueia ou veta a governança; a criação de um anel externo composto por unidades acadêmicas que impulsionam a inovação no interstício entre a universidade e a sociedade civil; a capacidade de envolver também as faculdades tradicionais da universidade no processo de transformação; a geração - a partir de atividades lucrativas - de um fluxo de recursos adicionais de livre disposição por parte do núcleo que dirige a instituição, e a geração e difusão de uma cultura organizacional favorável às mudanças (CLARK, 1998). 
Um elemento essencial é a existência de uma carteira diversificada para assegurar a renda, conformada em parte por negócios acadêmicos e pela administração do próprio patrimônio. A instituição deve gerar um excedente orçamentário capaz de fornecer subsídios internos cruzados a favor das unidades e atividades menos rentáveis da universidade e investir na ampliação das capacidades internas e do anel externo, que atua como elo com o meio. Um destacado administrador universitário inglês indica a esse respeito que "as universidades devem considerar que a geração de renda adicional, por si só, é de pouco valor a não ser que se possa demonstrar que a atividade que o produz proporciona um excedente utilizável" (SHATTOCK, 2003, p. 52). Isto sugere uma mudança considerável na gestão das universidades públicas, com a passagem de um financiamento quase exclusivamente estatal e garantido de forma legal ou político-burocrática para um financiamento diversificado, no qual a metade ou mais do orçamento da instituição é composta por rendas (públicas e privadas) diferentes da contribuição fiscal direta. Mas também, essa contribuição fiscal passa a ser sujeita a novas condições: concursos, licitações, fórmulas e financiamento por projetos, objetivos ou contratos. Em suma, é o uso de mecanismos de quase mercado ou de mercados administrados por parte dos governos (LE GRAND, 1991).

\section{Instituições dependentes de mercados privados}

Além disso, na região do TC mais próxima do vértice dos mercados privados e da sociedade civil, ocorre uma incessante atividade, tanto das universidades públicas como das privadas. Efetivamente, todas precisam e buscam desenvolver iniciativas e projetos que gerem renda e excedentes, como a cobrança de mensalidades e taxas aos estudantes nacionais e estrangeiros de graduação e pós-graduação; venda de serviços e produtos educativos e de conhecimento; terceirização de serviços de apoio e de bem-estar estudantil que passam a ser prestados comercialmente por agentes privados; locação da infraestrutura universitária; benefícios financeiros obtidos com a administração do patrimônio institucional; negócios de consultoria e outros realizados pelo pessoal acadêmico através de fundações e empresas universitárias; renda obtida de patentes e licenças, joint ventures com indústrias, venda de cursos virtuais, etc. (VARGHESE, 2009; SHATTOCK, 2003, p. 48-50). Um artigo recente do New Yorker sobre a Universidade de Stanford trata do alcance que podem ter essas atividades comerciais em uma universidade sem fins de lucro (AULETTA, 2012).

Concordo nesse ponto com os que afirmam que "embora as universidades públicas e privadas sem fins de lucro e as universidades lucrativas tenham tido 
em certa época grandes diferenças em suas missões, fontes de renda e serviços, nos últimos tempos têm convergido substancialmente em suas ações e nos usos de seus recursos. Certamente, continua havendo grandes diferenças em relação à renda, resultados e governança conforme os tipos de controle institucional; porém, com algumas exceções entre instituições de elite, essas diferenças tendem a tornar-se menos - e não mais - significativas" (PUSSER; TURNER, 2002, p. 5).

\section{A identidade da universidade pública}

Posso resumir o argumento aqui desenvolvido da seguinte maneira: afirmo que a identidade da universidade pública estatal moderna nasce da conjunção de duas narrativas - a Humboldtiana e a Napoleônica - que oferecem um padrão ideológico com o qual e avaliada a posição ocupada pela universidade no novo cenário global da educação superior. A vertente alemã, idealista-romântica, dá ao modelo de universidade pública ocidental uma elevada autoconsciência como parte integrante do Estado e expressão cultural da nação. Por outro lado, a vertente francesa, mais político-administrativa, concede a legitimidade e o reconhecimento como um serviço público de primeira ordem, como formadora das elites nacionais.

Diante desse padrão de comparação exigente e idealizado, a identidade contemporânea da universidade pública termina diminuída e sua posição no TC, descentrada e ameaçada. Ela já não é, estritamente falando, parte do serviço público de um Estado-de-cultura, mas um instrumento da sociedade civil para a sua competitividade na esfera do mercado global e da economia baseada na inovação e no conhecimento. Não é o órgão acadêmico autônomo que funda e expressa a mais elevada síntese da cultura nacional, mas uma parte da estrutura institucional responsável por produzir capital humano avançado e por valorizar o conhecimento requerido por um 'capitalismo acadêmico' expansivo. Por essa razão, já não atua como garantia de um Estado-docente que funda a República das Letras - cujo custo era financiado pela renda nacional - mas sim como um empreendimento sociocultural cujo modelo de negócio deve-se tornar sustentável mediante múltiplos contratos com diferentes partes interessadas, uma das quais é a administração do Estado.

Não preciso me aprofundar aqui sobre o amplo registro de contrastes utilizado para descrever e dramatizar as transformações ocorridas na universidade pública estatal na atualidade. Estas costumam ser representadas pela transição de Humboldt a Adam Smith, de Napoleão ao New Public Management, de uma universidade 
comunitária a uma universidade contratual, da colegialidade ao gerencialismo, do governo acadêmico colegial ou co-governo estamental à gerência dos administradores profissionais, de uma economia política da doação e do subsídio a uma do intercâmbio nos mercados, da solidariedade à concorrência, de uma cultura organizacional carismática e ritual a uma burocrática e de cálculos, de um controle de qualidade proporcionado pelo ethos profissional a um administrado mediante procedimentos de auditoria externa; enfim, a passagem da universidade como manifestação de uma ideia (estatal), como queriam Jaspers e a tradição alemã, para a universidade como organização que é resultado do novo jogo de forças no interior do TC.

Volta a surgir, assim, toda uma narrativa, desta vez negativa, sobre a distorção da 'Ideia de Universidade', noção tão profundamente arraigada - e invisivelmente presente - nos nossos debates sobre o passado, presente e futuro da instituição universitária.

De fato, boa parte do que hoje é entendido como 'crise da universidade pública'é o resultado da utilização de uma Ideia - aquela nascida das narrativas Humboldtiana e Napoleônica - como padrão para interpretar e julgar a universidade estatal contemporânea, nas suas diversas variantes de universidade corporativa, empreendedora, gerencial, militante, só de ensino, de pesquisa, nacional, de classe mundial, multiversidade, popular-massiva ou seletiva. Pois "entre a ideia e a realidade [...] cai a sombra", enuncia o verso de TS Elliot. O que aparece então é a degradação da Ideia, sua sombra entre escombros. O terrível anjo da história.

Mas, eu pergunto: que sentido faz essa operação ideológica e cognitiva que consiste em empregar uma 'Ideia da Universidade' para julgar suas figuras históricas?

Aqueles que se aventuram por esse caminho devem assumir sua posição em relação a Habermas, que, em certa ocasião, acusou Jaspers, autor de uma análise da universidade alemã à luz da Ideia da Universidade, como titulou o seu livro, de proceder sem dissimulação nem vergonha a partir das premissas derivadas de uma sociologia implícita do idealismo germânico, premissas que afirmam que "as instituições são formas do espírito objetivo. Só podem continuar funcionando enquanto encarnarem sua ideia inerente em uma forma viva. Assim que o espírito as abandona, elas se tornam rígidas e se transformam em algo puramente mecânico, como um organismo sem alma que se decompõe em matéria morta" (HABERMAS, 1997, p. 101). 
O mesmo vale, penso, para um bom número de análises sobre a crise e decadência da universidade público-estatal contemporânea. Ela é apresentada à sombra das poderosas narrativas que um dia serviram para celebrar sua identidade, como havendo abandonado sua essência original e traído sua Ideia inerente.

Mas as instituições não encarnam nem são a manifestação de uma Ideia ou espírito objetivo. Pelo contrário, são construídas e transformadas pelas forças que operam dentro delas, como organizações; a partir do Estado, e também da sociedade civil e dos mercados. Ou seja, pelas forças que em cada situação nacional constituem o TC. Dessa circunstância nascem também as condições necessárias para elaborar novas práticas discursivas sobre a universidade na América Latina.

Para concluir, menciono algumas que me parecem inevitáveis.

Primeiro, a necessidade de desconstruir as narrações em uso e as tradições nas quais se apoiam e assim livrar-se da ideia sobre a 'Ideia de uma Universidade'. Significa fazer a crítica e o desmantelamento não só dos vértices correspondentes ao Estado e à sociedade civil no $\mathrm{TC}$, mas também e especialmente, da própria universidade como organização realmente existente. Basta observar o escasso desenvolvimento dos estudos sobre a educação superior em nossa região para concluir que a arma da crítica é subutilizada e corre continuamente o perigo de ser substituída pelas narrações da vontade ou do desejo.

Em segundo lugar, a necessidade de dar prioridade aos contextos nacionais, ou estatal-nacionais em todo caso, dentro dos quais as universidades se desenvolvem. Considero que cedemos muito facilmente à noção de que os sistemas de educação superior estão em pleno processo de globalização, que as forças nacionais do TC foram subordinadas por forças internacionais e que as principais dinâmicas de mudança provêm, tanto no centro quanto nas periferias, da mesma fonte, seja ela sociedade do conhecimento, redes de informação, capitalismo das inovações ou, em termos culturais, modernidade tardia ou pós-modernidade.

Terceiro, a necessidade de considerar as peculiaridades dos sistemas mistos público-privados - de provisão como uma característica diferencial da educação terciária nas diferentes periferias do mundo, especialmente na América Latina, onde, como vimos, de cerca de 4 mil universidades existentes, dois terços são privadas, reunindo atualmente este setor mais de $50 \%$ da matrícula total. O que 
significa que nesta região existe uma dialética público/privada particularmente intensa, embora desigual entre países, em diferentes dimensões e aspectos: organizacionais, de vinculação das instituições com o Estado, de inserção na sociedade civil e nos mercados, financiamento, seletividade acadêmica e social e de culturas institucionais. Deveríamos ser líderes de pesquisa neste aspecto. Mas estamos longe disso.

Quarto, há também na América Latina um predomínio quantitativo de universidades exclusivamente voltadas para o ensino. De fato, só cerca de $5 \%$ do total de nossas instituições universitárias podem ser consideradas como universidades de tradição Humboldtiana, no sentido de combinar de maneira relativamente sistemática as funções de pesquisa e ensino, pelo menos na pósgraduação. As restantes, no entanto, não são instituições de alta especialização e formação de quadros superiores do Estado, conforme o modelo Napoleônico, nem se ajustam ao modelo descrito pelo Cardeal Newman na sua Ideia da Universidade, na qual proclamava como o mais alto padrão formativo o cultivo do caráter e da distinção do gentleman. Em vez disso, são parte de una maquinaria cada vez mais massiva de certificação; emitindo certificados cujo valor educacional, o vínculo com o mercado de trabalho e a capacidade de conferir distinção e status mal começamos a estudar (BRUNNER, 2009, p. 382-395).

Finalmente, a necessidade de considerar seriamente se nas atuais condições é possível a criação, manutenção, restauração ou renovação - conforme a perspectiva escolhida por cada um - de um modelo crítico-deliberativo de universidade pública e a existência de universidades privadas que pudessem encaixar neste modelo. De fato, o desafio "é como criar condições para o estabelecimento de uma esfera pública sustentável por meio da educação superior" (PUSSER, 2012, p. 40).

Dentro das instituições, isso exige organizações capazes de um alto grau de autorreflexão e deliberação sobre suas próprias práticas, em condições de atuar com autonomia acadêmica e de inovar no seu trabalho de criação, preservação, transmissão e aplicação do conhecimento. Não está claro se sob a pressão do empreendimento, ou de uma burocrática "gaiola de ferro", é possível atingir tais níveis de autorreflexão. Também não são claros quais arranjos de governo e gestão, de financiamento das funções universitárias, de provisão de ensino e de organização do trabalho de pesquisa levam, mais que outros, a essa intensa deliberação sobre as próprias práticas da universidade. 
Fora das instituições, foi sugerido que criar uma esfera pública por meio da educação superior poderia manter sob controle as forças que moldam o trabalho das instituições; dito com a metáfora do TC, obter um equilíbrio entre as forças das próprias corporações, o Estado, a sociedade civil e os mercados (PUSSER, 2012). De maneira mais realista, a aspiração deveria ser a um equilíbrio instável entre essas forças, pois resulta utópico pensar que seria possível chegar a um ajuste perfeito e sem fricções induzido seja pelos meios político-administrativos do Estado, pela mão invisível da concorrência, pela interação dos diversos interesses da sociedade civil, seja pela mera autorregulação das instituições e pelo altruísmo da profissão acadêmica.

A história da universidade moderna mostra que desse equilíbrio instável nascem as mudanças e a inovação institucionais e que, ao contrário, quando uma dessas forças se torna absolutamente hegemônica e suprime as restantes, sobrevêm períodos de estancamento ou de crise.

Santiago do Chile, 22 de novembro de 2013

\section{Referências}

AARREVAARA, T.; DOBSON, I. R.; LEANDER, C. Brave new world: Higher education reform in Finland. Higher Education Management and Policy, v. 21/22, n. 13, p. 1-18, 2009.

ABELLÁN, J. La idea de universidad de Wilhelm von Humboldt. In: ONCINA COVES, F. Filosofía para la Universidad: Filosofía contra la Universidad (de Kant a Nietzsche). Madrid: Universidad Carlos III; Editorial Dykinson, 2009, p. 273-296.

ANDERSON, P. B. An insight into ideas surrounding the 2003 University Law. Working Papers on University Reform, Working Paper 04, Danish University of Education, 2006. Disponível em: $<$ http://www.dpu.dk/fileadmin/www.dpu. $\mathrm{dk} /$ forskning/forskningsprogrammer/epoke/workingpapers/061201171547amp-type-doc >. Acesso em: 22 nov. 2013.

AULETTA, K. Get-rich university, The New Yorker, April 30, 2012, p. 38-47. 
BOK, D. Universities in the Marketplace: the commercialization of higher education. Princeton, NJ: Princeton University Press, 2003.

BRUNNER, J. J. Educación Superior en Chile: instituciones, mercados y políticas gubernamentales (1967-2007). Santiago, Chile: Ediciones Universidad Diego Portales, 2009.

BRUNNER, J. J.; FERRADA, R. Educación Superior en Iberoamérica: Informe 2011. Santiago, Chile: CINDA, Universia, FundacionTelefónica y Banco Mundial, 2011.

CLARK, B. R. Creating Entrepreneurial Universities: organizational pathways of transformation. Oxford, UK: Pergamon Press, 1998.

. The Higher Education System: academic organization in cross-national perspective. Berkeley, CA: University of California Press, 1983.

FÄGERLIND, I.; STRÖMQVIST, G. Reforming Higher Education in the Nordic Countries. Paris: IIPE-UNESCO, 2004.

FALLON, D. The German University: a heroic ideal in conflict with the modern world. Boulder, Colorado: Colorado Associated University Press, 1983.

HABERMAS, J. The idea of the university: learning process. In: HABERMAS, J. The New Conservatism: cultural criticism and the historian's debate. Cambridge, MA: The MIT Press, 1997, p. 100-127.

HAZELKORN, E. Rankings and the Reshaping of Higher Education: the battle for world-class excellence. London: Palgrave Macmillan, 2011.

HEGEL, G. W. RasgosFundamentales de la Filosofía del Derecho. Madrid: Biblioteca Nueva, 2000. (1821).

JENSEN, H. S. Collegialism democracy and university governance: The case of denmark. working papers on university reform, working paper 15, danish school of education, university of ahrhus, 2010. Disponível em: $<\mathrm{http}: / /$ du.au.dk/ fileadmin/www.dpu.dk/forskning/forskningsprogrammer/epoke/workingpapers/ WP_15.pdf >. Acesso em: 22 nov. 2013. 
KAUKO, J.; DIOGO, S. "Comparing higher education reform in Finland and Portugal: different contexts, same solutions? Higher Education Management and Policy,[S.1.], v. 23/3, n. 17, p. 115-135, 2011.

KWIEK, M. The University and the State: a study into global transformations. Frankfurt am Main: Peter Lang, 2006.

LE GRAND, J. Quasi-markets and social policy. The Economic Journal, n. 101, p. 1256-1267, 1991.

LELIÈVRE, C. The French model of the educator state. Journal of Education Policy, [S.1.], v. 15, n. 1, p. 5-10, 2000.

LEVY, D. Las múltiples formas de la educación superior privada: Un análisis global. In: BRUNNER, J. J. Y PEÑA, C. El Conflicto de las Universidades: entre lo público y lo privado. Santiago, Chile: Ediciones Universidad Diego Portales, 2011, p. 135-160.

ROWE, L. S. Instruction in French Universities: with special reference to instruction in public law and economics in the law faculties. Annals of the American Academy of Political and Social Science, [S.1.], v. 2, p. 62-85, jan., 1982.

MARGINSON, S. Clark Kerr and the uses of the university: CSHE Ideas and Issues in Higher Education Seminar. 15 dez., 2008. Disponível em:

$<$ http://www.cshe.unimelb.edu.au/research/res_seminars/issues_ideas/2008/docs/ ClarkKerr15Dec08.pdf > . Acesso em: 22 nov. 2013.

NEAVE, G. The European dimension in higher education: An excursion into the modern use of historical analogues. In: HUISMAN, J., MAASSEN, P. Y NEAVE, G. Higher Education and the Nation State: the international dimension of higher education. Oxford: Pergamon, 2001, p. 13-73.

NYBOM, T. A rule-governed community of scholars: the humboldt vision in the history of the European university. In: MASSEN, P.; OLSEN, J. P. (Eds.) University Dynamics and European Integration. Dordrecht, The Netherlands: Springer, 2007, p. 55-79. 
PUSSER, B. Power and authority in the creation of a public sphere trough higher education. In: PUSSER, B., KEMPER, K., MARGINSON, S. AND ORDORIKA, I. Universities and the Public Sphere: Knowledge Creation and State Building in the Era of Globalization. New York; London: Routledge; Taylor \& Francis Group, 2012, p. 27-46.

PUSSER, B.; TURNER, S. E. The challenge of convergence: Nonprofit and forprofit governance in higher education. Paper prepared for meeting of the Cornell Higher Education Research Institute, Ithaca, New York, June 3-4, 2002, p. 1-36.

SHATTOCK, M. Managing Successful Universities. Maidenhead, England: Society for Research into Higher Education \& The Open University, 2003.

SLAUGHTER, S.; RHOADES, G. Academic Capitalism and the New Economy: markets, state, and higher education. baltimore and london. The Johns Hopkins University Press, 2004.

VALIMAA, J. The corporatization of national universities in Finland. In: PUSSER, B., KEMPER, K., MARGINSON, S.; ORDORIKA, I. (2012) Universities and the Public Sphere: knowledge creation and state building in the era of globalization. New York; London: Routledge, Taylor \& Francis Group, 2012, p. 101-119.

VARGHESE, N. V. Higher education reforms: institutional restructuring in Asia. Paris: IIPE-UNESCO, 2009.

VAUGHAN, M.; ARCHER, M. S. Social Conflict and Educational Change in England and France: 1789-1848. Cambridge, UK: Cambridge University Press, 1971.

Recebido em: 12/06/2013

Aceito para publicação em: 22/11/2013 


\section{The idea of the public university: contrasting narratives Abstract}

The various narratives --or practical discourse-- that make up the self-awareness and ideology of the modern public state universities have been subject to intense examination. The present article describes the core models of these narratives --simply put as Humboldtian and Napoleonic-- with their different evolutions and expressions in various contemporary higher education environments. The discussion shows that the 'idea of the public or state university', developed by these narratives, are quite dramatically distinct in the present day. Today the public university lacks a narrative, an explanation of itself, and a sense of how to account for new organizational forms and practices of knowledge production, transmission and management. Given these antecedents, the article makes proposals to refresh the practical discourse of public/state universities in Latin America and examines the possibility of a critical-deliberative model for both public and private universities. Keywords: University. Historical models. Estate. Public.

\section{La idea de la Universidad pública: narrativas contrastantes \\ Resumen}

Las diversas narrativas --o prácticas discursivas-- que forman parte de la autoconciencia y la ideología de la moderna universidad público-estatal han sido objeto últimamente de un intenso examen. Este artículo describe los modelos fundantes de aquellas narrativas --Humboldtiano y Napoleónico, para simplificar-- y luego los contrasta con algunas de sus evoluciones y nuevas manifestaciones en diversos escenarios actuales de la educación superior. Muestra que la 'idea de la universidad'público-estatal, elaborada originalmente por esas narrativas, se aparta drásticamente de las condiciones presentes en que esta institución existe y se desenvuelve. Hoy la universidad pública carece de una narrativa, de una explicación de sí misma y de un sentido que acompañe a sus nuevas formas de organización y prácticas de producción, transmisión y gestión de conocimientos. A la luz de estos antecedentes se plantean algunas ideas para la renovación de estas prácticas discursivas en América Latina y se indaga sobre la viabilidad de un modelo crítico-deliberativo de universidad pública y de universidades privadas que pudieran adscribirse a este modelo.

Palabras claves: Universidad. Modelos históricos. Estado. Público. 